\title{
Anatomical and nutritional requirements for induction and sustained growth in vitro of Cymodocea nodosa (Ucria) Ascherson
}

\author{
Pilar García-Jiménez, Eva P. Navarro, Cristo H. Santana, \\ Ángel Luque, Rafael R. Robaina* \\ Departamento de Biología, Universidad de Las Palmas de Gran Canaria, 35017 Las Palmas de Gran Canaria, \\ Gran Canaria, The Canary Islands, Spain
}

Received 13 July 2004; received in revised form 20 June 2005; accepted 6 July 2005

\begin{abstract}
In vitro methods of plant micro-propagation are being considered as a possible solution for the decline in seagrass communities registered worldwide. To achieve successful plant micro-propagation, culture conditions are commonly adjusted empirically within almost species-specific conditions, to comply to the following three conditions: (i) culture establishment (ii) shoot production and (iii) rooting and hardening for planting in soil. Cultures of Cymodocea nodosa were established from axenic explants of the apical meristem (approx. $0.5 \mathrm{~cm}$ ) which regenerated new leaf or produced leaf regenerating calli (5\% of cultivated explants) in media containing $10^{-6} \mathrm{M}$ of the cytokinin analogue TDZ. Longer ramet explants, not fully axenic, containing internode with leaf and roots were also affected by $10^{-6} \mathrm{M}$ cytokinins and auxin type of regulators, as they promoted leaf extension (in $\mathrm{cm}$ ), particularly GA. None of the explants progressed further to massive shoot propagation and new plantlet production. Instead, experiments made with ramet explants which simulated potential produced plantlet revealed that there seems to be a strong interaction within leaf, rhizome and root, since the carbon fixed in the leaf was rapidly translocated to the rest of the tissue (50\% in the roots in a FW basis). The explants preferred ammonium and dihydrogen inorganic phosphate as a nutrient source, efficiently assimilating the former regardless of whether such were added to the underground or surface tissue. However, underground tissue was required to maintain $P$ status in the cultivated explants.
\end{abstract}

(C) 2005 Elsevier B.V. All rights reserved.

Keywords: Cymodocea nodosa; Explant anatomy; Growth substance; In vitro; Nitrogen; Phosphorus

\section{Introduction}

The seagrass Cymodocea nodosa (Ucria) Ascherson forms dense submerged, ecologically relevant communities as stable and protected habitats, where other vegetation, animals and biota live, spawn and feed. Anthropogenic activities have influenced coastal marine ecosystems to the extent that they are considered to be responsible for the worldwide decline in seagrass communities. Several strategies such as transplantation and micropropagation may help to avoid complete depletion. Transplantation depends on a source (threatened) population and its rates of reproductive or vegetative propagation, which are commonly slow (West et al., 1990; Molenaar et al., 1993; Molenaar and Meinesz, 1992, 1995).

\footnotetext{
* Corresponding author. Tel.: +34 928 452904; fax: +34 928452922.

E-mail address: rrobaina@dbio.ulpgc.es (R.R. Robaina).
}

Micropropagation is the propagation of plant species in vitro starting from its cells, tissues or, organs. This can be carried out in a shorter time than conventional vegetative propagation, and produces high biomass from one single plant. In the 1970s Murashige stated that three developmental stages of propagation seems to be mandatory: (i) culture establishment, (ii) shoot production and (iii) rooting and hardening for planting in soil. Using these ground rules, micropropagation of freshwater aquatic plants was successfully carried out concluding in normal and healthy plants (Huang et al., 1994; Agrawal and Mohan Ram, 1995; Kane et al., 1999).

Interesting studies have been produced, aimed at in vitro culture and/or propagation of ecologically relevant marine species, such as Posidonia oceanica, Ruppia maritima or C. nodosa. Whilst it is clear that it is possible to apply the essentials of in vitro methodology to establish explant cultures (i.e. stage I), massive shoot induction, rooting control and plant production (stages II and III) comparable to that of other 
aquatic plants, such as the above mentioned species, have not been achieved (Loquès et al., 1990; Koch and Durako, 1991; Terrados-Muñoz, 1995; Bird et al., 1993, 1996, 1998).

In spite of the relevance of these physiological traits to the success of in vitro propagation of seagrasses, nothing is known about the actual or potential nutritional situation of the explants and plantlets produced in culture. The ecophysiological literature relating to these problems commonly addresses the question in the light of the respective roles of root versus leaf as the organ involved in nutrient absorption (commonly $\mathrm{N}$ and $\mathrm{P}$ ). This is the same in the case of the acquisition of carbon, its fixation and allocation during photosynthesis, although it is clear that seagrasses translocate oxygen and carbon from leaf to non-photosynthetic tissues (Pérez et al., 1994; Terrados and Williams, 1997; Kraemer and Mazzella, 1999; Touchette and Burkholder, 2000a,b). In fact, clone identity experiments revealed that the subsistence of an apical meristem in C. nodosa seems to depend on the rhizome (up to $50 \mathrm{~cm}$ Terrados et al., 1997).

In this work, explants of C. nodosa, containing only the apical meristem, or a ramet, containing the internode, leaf, and associated root (i.e. simulating plantlet), were cultivated under different nutritional conditions, which included plant growth regulators, and nitrogen and phosphorus sources to determine: (i) the effect of growth regulators, (ii) the preferred chemical form of the nutrients and (iii) the relative importance of the underground and overground parts of the explant in N, P and C assimilation. This was an attempt to clarify whether growth regulators affect growth, to optimise the type and form of addition to the culture vessel of the limitant nutrients, and to evaluate to what extent both parts are necessary to avoid poor nutritional status during the propagation of the regenerated plantlet during stages II and III of propagation.

\section{Materials and methods}

\subsection{Plant material}

Samples of $C$. nodosa (Ucria) Ascherson were collected at Castillo del Romeral (on the southeast coast of Gran Canaria, the Canary Islands, $27^{\circ} 48^{\prime} 00^{\prime \prime} \mathrm{N} ; 15^{\circ} 25^{\prime} 40^{\prime \prime} \mathrm{W}$ ) from shore pools of 1-2 m depth. To avoid any damage to the populations, the experiments were regularly carried out with material collected in the Winter and Spring of the years from 2001 to 2003. Within $2 \mathrm{~h}$ after collection, the youngest and cleanest plant material was selected at the laboratory, where explants of approx. $3 \mathrm{~cm}$ consisting of internode rhizome, leaf, and associated root were excised from the rhizome (henceforth ramets, Fig. 1). Leaves from ramets were further cut transversely in order to analyse the effect of regulators on new leaf tissue generation (meaning both the growth $(\mathrm{cm})$ of the young leaf and new leaf tissue produced by those that were cut off). Explants were surface sterilized previous to cultivation, by dipping in distilled water and immersion in $1 \%$ sodium hypochloride in autoclaved seawater for $5 \mathrm{~min}$. After rinsing three times in sterile seawater, explants were incubated for $48 \mathrm{~h}$ with a filter-sterilized antibiotic mixture containing rifampicin, penicillin, nystatin, ampicillin (150 $\mathrm{mg}^{-1}$ each) and germanium dioxide $\left(5 \mathrm{mg}^{-1}\right)$. This method produced not axenic cultures of such a centimeter long explants, but together with sterilization through autoclaved seawater, nutrient solutions, sand and the culture vessel, ensured they were clean enough to avoid contaminant overgrowth and interference during the experimental time (up to 15 days). Axenic explants were obtained from cylindrical fragments $(0.5 \pm 0.1 \mathrm{~cm})$ excised from the meristematic apex of the plagiotropic rhizome (henceforth, apical explants).

\subsection{Culture conditions}

To check the effects of plant growth regulator (PGRs) auxins, indole acetic acid (IAA), indole butyric acid (IBA), 2,4dichlorophenoxyacetic acid (2,4-D); cytokinins, kinetin (KIN), benzyladenine (BA), $N$-phenyl- $N^{\prime}$-1,2,3-thidiazol-5-ylurea (thidiazuron or TDZ), and gibberellic acid (GA) were added individually as filter-sterilised stock solutions at $10^{-6} \mathrm{M}$ final concentration ramets were cultured in $30 \mathrm{ml}$ Provasoli's medium (PES, Provasoli, 1968) in tubes, supplemented with the respective growth regulator. Axenic apical explants were cultivated in solidified (agar 0.8\%) PES medium (prepared with diluted seawater to adjust the osmolarity to that of the seawater; Robaina et al., 1990) in Petri dishes, supplemented with $10^{-6} \mathrm{M}$ of the same regulators and sucrose $60 \mathrm{~g} 1^{-1}$. Preliminary experiments carried out with most of the regulators tested did not reveal the existence of a clear dose response, thus effective concentration was directly adjusted to $10^{-6} \mathrm{M}$ as a standard hormonal concentration ramets and apical explants were kept for 15 days in their respective media. Experiments were repeated three times with five replicates of each regulator (i.e. 15 ramets and 15 apical explants per growth regulator).

Enriched seawater Provasoli medium in Magenta ${ }^{\circledR}-\mathrm{G} 7$ (Sigma Co.) culture vessels was used as a culture medium in the experiments with nutrients. The vessels were filled with $40 \mathrm{ml}$ autoclaved sand and $200 \mathrm{ml}$ of liquid culture medium as shown in Fig. 1. Enrichment of the medium was achieved by adding nutrients from sterilized stock solutions to the seawater. Nutrient enriched sand was obtained by incubating autoclaved sand during 4 days in the appropriate nutrient solution. To check nutritional preferences for different chemical forms of $\mathrm{N}$ and $\mathrm{P}$, a simplified factorial experimental design of BoxBehnken was used (Tox and Behnken, 1969) for three factors (nitrate, glutamic, ammonium, for $\mathrm{N}$, and inorganic $\mathrm{KH}_{2} \mathrm{PO}_{4}$ and organic glyceraldehyde-3-phosphate for $\mathrm{P}$ ) with three concentration levels based on regular PES enrichment of sand and water $(0,0.05,0.1 \mathrm{mM}$, and $0,0.5,1 \mathrm{mM}$ phosphorus and nitrogen, respectively) and three central points. A semiquantitative response variable $(\mathrm{GH})$ was used to measure greenness and youthful vigor of leaves during the experimental time (15 days). One ramet per vessel (Fig. 1) was used together with five replicates per treatment $(\mathrm{GH}=1$ no evident change or even degeneration symptoms, $\mathrm{GH}=2$ healthy as pigmented, and $\mathrm{GH}=3$ healthy and regenerating new leaves. Fig. 1C and D). The entire experimental design was performed twice with five 




Fig. 1. In vitro culture of Cymodocea nodosa. (A) Leaf regenerating callus growing from an axenic apical explant, obtained after 15 days in media supplemented with $10^{-6} \mathrm{M}$ of the synthetic cytokinin $N$-phenyl- $N^{\prime}-1,2,3$-thidiazol-5-ylurea (thidiazuron or TDZ). (B) Ramet with node, leaves and associated roots, over the grid used to homogenize size. ( $\mathrm{C}$ and $\mathrm{D})$ Growth of healthy explant after 15 days in culture vessels (i.e. $\mathrm{GH}=3$ ) with sandy ground and overlying water layer used in this study (note the extension of the leaves towards the surface, arrow). Scale bar $0.2 \mathrm{~cm}$ in part (A), and $1 \mathrm{~cm}$ in the rest.

replicates (i.e. 10 ramets per treatment). Here, we present the pooled data.

\subsection{Leaf versus root nutrient assimilation}

Once reduced $\mathrm{N}$ and inorganic form of $\mathrm{P}$ were determined as the preferred chemical form, experiments were performed to check whether these nutrients were being absorbed by the ramets preferably from the enriched water (i.e. overground tissue) or from the enriched sand (i.e. underground tissue) prepared as described above. Short-term design $(48 \mathrm{~h})$ was performed in order to avoid any increase of biomass that may dilute assimilated nutrients. The water and/or the sand part of the cultivation system in the culture vessel was enriched with $1 \mathrm{mM}$ ammonium or $0.1 \mathrm{mM} \mathrm{KH}_{2} \mathrm{PO}_{4}$, and the content of each nutrient in the ramet was analysed. A series of experiments were performed to check whether kinetin addition $\left(10^{-6} \mathrm{M}\right)$ might also contribute to $\mathrm{N}$ and $\mathrm{P}$ assimilation by the explants.

The content of nitrogen $(\% \mathrm{~N})$ and phosphorus $(\% \mathrm{P})$ were determined in dried powdered plant material cultivated in each of the conditions tested ( $n=6-9$ samples per treatment). Nutrients were extracted and determined colorimetrically following standard methods for plant analysis (Walinga et al., 1995). As a reference of nutrient contents, some samples 
of C. nodosa (the whole plant powder) were send to Estación Experimental of Zaidin (CSIC, Granada, Spain), a reputed reference laboratory for nutrient content in plants. There, $\mathrm{N}$ and $\mathrm{P}$ were determined colorimetrically after microwave-assisted digestion of vegetal material.

\subsection{Carbon fixation}

Inorganic carbon fixation was monitored by incubating the ramets $(n=3)$ for $90 \mathrm{~min}$ in $20 \mathrm{ml} \mathrm{PES}$ with $0.5 \mu \mathrm{Ci}\left[{ }^{14} \mathrm{C}\right]-$ $\mathrm{NaHCO}_{3}\left(42.6 \mathrm{mCi} \mathrm{mmol}^{-1}, 1.6 \mathrm{GBq} \mathrm{mmol}^{-1}, \mathrm{NEN}, \mathrm{UK}\right)$ and $70 \mu \mathrm{mol}$ photons $\mathrm{m}^{-2} \mathrm{~s}^{-1}$, provided by daylight fluorescent at the level of the incubation vessel. After incubation, $\mathrm{HCl}_{4} \mathrm{~N}$ was added to remove the remaining $\left[{ }^{14} \mathrm{C}\right]-\mathrm{NaHCO}_{3}$, and the ramets were split into leaf, rhizome and roots to be extracted and the fixed dpm counted separately. Carbon fixation rates were calculated using the equation:

fixed carbon $\left(\mathrm{mg} \mathrm{Ch}^{-1}\right)=\frac{\mathrm{dpm} \mathrm{S} \mathrm{DIC} 1.05}{\mathrm{dpm} \mathrm{T} t}$

where dpm $\mathrm{S}$ is the dpm in the DMSO $(10 \mathrm{ml})$ soluble fraction of each leaf, rhizome and root sample; DIC is the carbon (mg C) in $20 \mathrm{ml}$ of media with $1.86 \mathrm{mM}$ dissolved inorganic carbon; 1.05 is a correction factor; $\mathrm{dpm} \mathrm{T}$ is the total dpm added to the incubation vessel; and $t$ is the time in hours. Data were normalized to $\mathrm{g} \mathrm{FW}$ and $\mathrm{mg} \mathrm{Chl} a$ in the leaf, by extracting $90 \%$ acetone and quantified spectrophotometrically using the equations of Jeffrey and Humphrey (1975).

\subsection{Statistics}

Analysis of the Box-Behnken simplified factorial design for $\mathrm{N}$ and P Statgraphics Plus 5.1 statistical software (Statistical Graphics Co, MA, USA). Tukey HSD post hoc test (SPSS 13.0. SPSS Inc., IL, USA) was used for multiple comparison of data from the experiments with $\mathrm{N}, \mathrm{P}$, and PGR's enrichment.

\section{Results}

None of the plant growth regulators tested promoted growth or regeneration in apical explants, but outstanding results were obtained with $N$-phenyl- $N^{\prime}-1,2,3$-thidiazol-5-ylurea (TDZ) since leaf regeneration was observed in $80 \%$ of the explants, and leaf regenerating callus were to be observed sprouting from the edge of the explants (Fig. 1A) in a frequency of up to $5 \%$ of the cultivated explants. Neither the calli nor the leaflet progressed further as they browned and died off after a few weeks. In the larger not fully axenic explants, plant growth regulators influenced both new leaf regeneration and extension in ramet explants (Fig. 2), with the highest records for gibberellic acid. Indole butyric acid (IBA) was apparently inhibitory as compared to the rest.

The results on nutrient preferences are presented in Table 1 and Fig. 3. Block design revealed that, in terms of the $\mathrm{GH}$ variable, ammonium and inorganic phosphate sustained better the ramet as they were the most significant factors explaining up to $94 \%$ of the variance of the GH observed (Table 1).

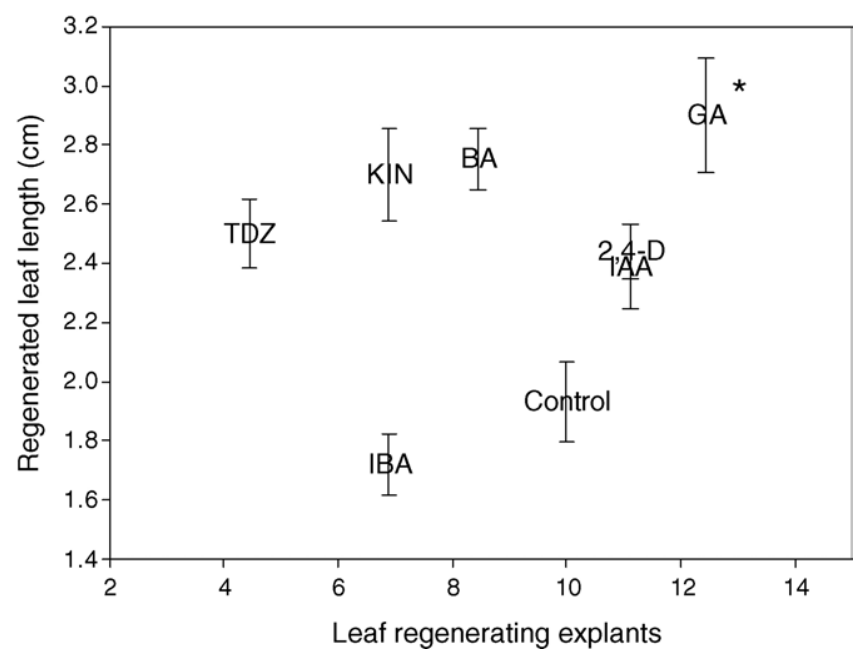

Fig. 2. Effect of plant regulators on the length of the leaf tissue and number of not fully axenic ramet explants showing leaf extension after 15 days in culture (mean \pm S.E., $n=5$ in three replicates). All regulators were supplemented at $10^{-6} \mathrm{M} . \mathrm{IAA}=$ indole acetic acid, IBA $=$ indole butyric acid, 2,4-D = 2,4 dichlorophenoxyacetic acid, $\mathrm{KIN}=$ kinetin, $\mathrm{BA}=$ benzyladenine, $\mathrm{TDZ}=\mathrm{N}$ phenyl- $N^{\prime}-1,2,3$-thidiazol-5-ylurea or thidiazuron, $\mathrm{GA}=$ gibberellic acid. ( $\left.{ }^{*}\right)$ denotes significant difference with control $(P<0.05)$.

Short-term experiments of $\mathrm{N}$ and $\mathrm{P}$ enrichment, revealed that, as compared to control plants, $\mathrm{N}$ status was kept in all cultivated explants, regardless of whether it was added to the water or to the sand. Only explants cultivated in sand enriched

Table 1

Analysis of the Box-Behnken simplified factorial design for $\mathrm{N}$ and $\mathrm{P}$ (including ammonium as the best $\mathrm{N}$ source)

\begin{tabular}{|c|c|c|c|c|}
\hline Source & d.f. & Mean squares & $F$-ratio & $P$-value \\
\hline A: nitrate & 1 & 2.0 & 5.71 & 0.062 \\
\hline B: glutamic acid & 1 & 1.125 & 3.21 & 0.133 \\
\hline C: ammonium & 1 & 10.125 & 28.93 & 0.003 \\
\hline AA & 1 & 0.923 & 2.64 & 0.165 \\
\hline $\mathrm{AB}$ & 1 & 2.25 & 6.43 & 0.052 \\
\hline $\mathrm{AC}$ & 1 & 0.25 & 0.71 & 0.436 \\
\hline $\mathrm{BB}$ & 1 & 0.230 & 0.66 & 0.453 \\
\hline $\mathrm{BC}$ & 1 & 0 & 0 & 1.000 \\
\hline $\mathrm{CC}$ & 1 & 2.076 & 5.93 & 0.058 \\
\hline $\begin{array}{l}\text { Total error } \\
r^{2}=75.98 \%\end{array}$ & 5 & 0.35 & - & - \\
\hline A: ammonium & 1 & 2.076 & 41.54 & 0.001 \\
\hline B: $\mathrm{KH}_{2} \mathbf{P O}_{4}$ & 1 & 1.125 & 22.5 & 0.005 \\
\hline C: Glyceraldehyde-3P & 1 & 0.932 & 18.46 & 0.007 \\
\hline AA & 1 & 1 & 0.125 & 2.5 \\
\hline AB & 1 & 4 & 80 & 0.003 \\
\hline $\mathrm{AC}$ & 1 & 0.25 & 5 & 0.075 \\
\hline BB & 1 & 2.076 & 41.54 & 0.001 \\
\hline $\mathrm{BC}$ & 1 & 0.25 & 5 & 0.075 \\
\hline $\mathrm{CC}$ & 1 & 0.5 & 10 & 0.250 \\
\hline $\begin{array}{l}\text { Total error } \\
r^{2}=94.03 \%\end{array}$ & 5 & 0.05 & - & - \\
\hline
\end{tabular}

The ANOVA table partitions the variability in GH (growth and health variable) for each of the effects, and test the statistical significance of each factor by comparing the mean squares against an estimate of the experimental error. Significant effects are in bold letter $(P<0.050) . r^{2}$ statistic indicates the percentage of the variability of GH explained by the model. 

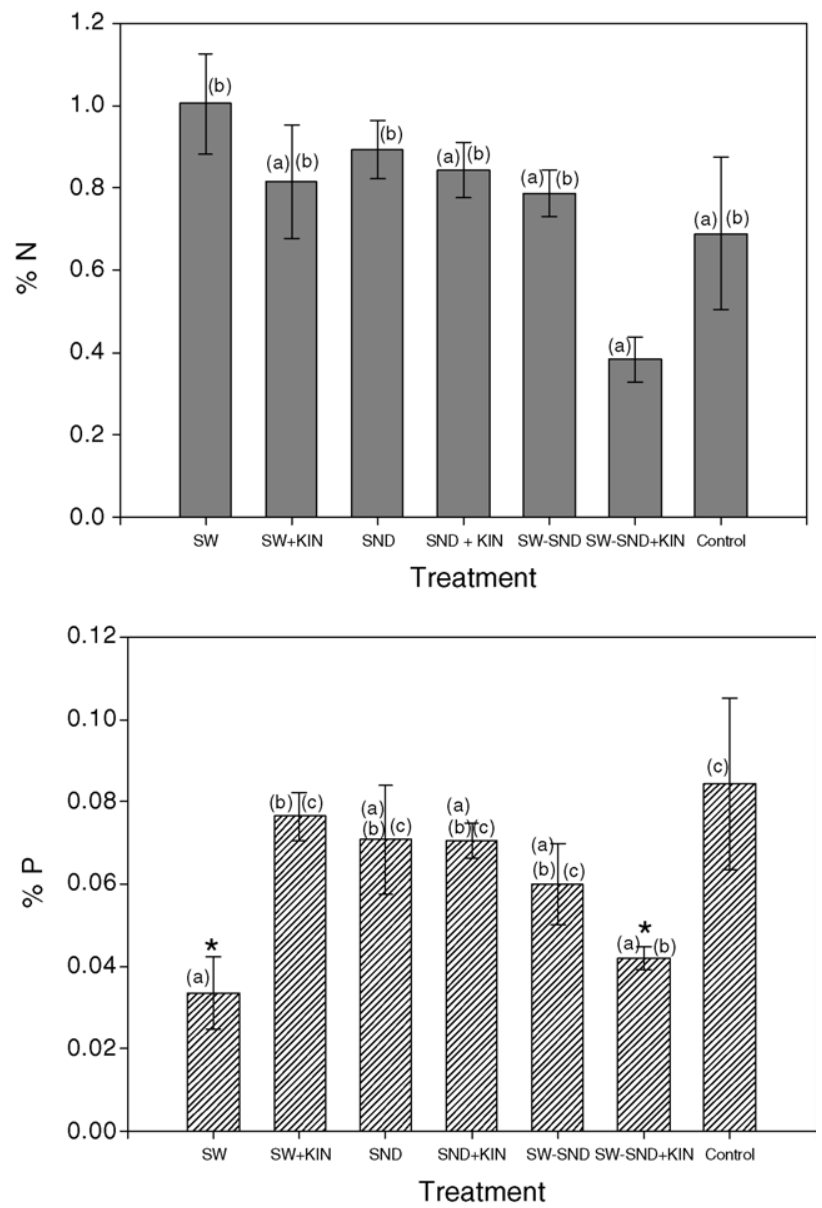

Fig. 3. Nitrogen $(\% \mathrm{~N})$ and phosphorus $(\% \mathrm{P})$ assimilation by the explants cultivated ( 2 days) in $1 \mathrm{mM}$ ammonium or $0.1 \mathrm{mM} \mathrm{KH}_{2} \mathrm{PO}_{4}$, in the presence or absence of kinetin $\left(10^{-6} \mathrm{M}\right)$. Nutrient supplementation was carried out in the water (SW), in the sand (SND) or in both (SW-SND). Bars are means of six to nine replicates. Vertical lines are S.E. Same letter over the bar denotes homogeneous group of means. $\left(^{*}\right)$ denotes significant difference with control $(P<0.05)$.

with $P$ could kept $P$ status, since ramets in water enriched with $P$ showed a significant lost. Kinetin addition to sand and water also caused significant loss of both $\mathrm{N}$ or P. Its addition to the water together with $\mathrm{P}$ enrichment could contribute towards maintaining its status (Fig. 3).

Rapid translocation of the fixed carbon from the leaf, as the point of fixation, to the rhizome and to the roots (Table 2) was observed after $90 \mathrm{~min}$ in presence of the radioactive inorganic carbon source.

Table 2

Carbon fixation rate and allocation after $90 \mathrm{~mm}$ of plant incubation in radioactive inorganic carbon $(n=3)$

\begin{tabular}{lcl}
\hline & $\mathrm{Chl} a\left(\mathrm{mg} \mathrm{C} \mathrm{h}^{-1} \mathrm{mg}^{-1}\right)$ & $\mathrm{FW}\left(\mathrm{mg} \mathrm{C} \mathrm{h}^{-1} \mathrm{mg}^{-1}\right)$ \\
\hline Leaf & $0.185 \pm 0.03(30 \%)$ & $0.55 \pm 0.044(14 \%)$ \\
Rhizome & $0.26 \pm 0.07(43 \%)$ & $1.26 \pm 0.020(34 \%)$ \\
Root & $0.16 \pm 0.04(26 \%)$ & $1.92 \pm 0.015(52 \%)$
\end{tabular}

Data are mean \pm S.E. Percentage in each organ of the total carbon fixed are in parentheses.

\section{Discussion}

The effectiveness of plant growth regulating substances (PGRs) is essential to complete the micropropagation of $C$. nodosa since this will depend on the availability of feasible PGR formulations to induce organized growth from explants and to propagate the plantlets that were produced. The effect of plant growth regulators has been previously reported in seagrasses, such as $P$. oceanica and $R$. maritima, in which cytokinin induced shoot and rhizome growth (Loquès et al., 1990; Koch and Durako, 1991) whilst auxin increased shoot growth and branch production in rhizome segments obtained from seeds in Halophila decipiens (Bird et al., 1998). Recently, auxin naftal and IBA were reported to increase root emergence and growth in seedlings of $P$. oceanica (Balestri and Bertini, 2003). In $C$. nodosa, Terrados-Muñoz (1995) reported the effects of GA on leaf growth in explants from the rhizome. In this work, small apical meristem explant cultures could be established under axenicity, thus producing new leaflet or leaf regenerating calli when TDZ, a cytokinin-like substance first used for recalcitrant woody species (Chevreau et al., 1989), was added to the medium. On the other hand, non-axenic ramet explants regenerated new leaf tissue as a result of the treatment with all the plant growth regulators tested, particularly GA. Our results and previous reports support that seagrasses, like other aquatic plants and terrestrial counterparts, may acclimatise well to in vitro culture conditions to complete a stage I of culture establishment reactive to PGRs. However, it seems rather difficult to progress further to stages II and III of the propagation since even the axenic calli did not progress to develop stage II plantlet.

In this respect, the experiments made with ramet explants may contribute to improve the culture requirements of future regenerated plantlets since, it seems (Table 2, Fig. 3) that there is a close interconnection within the leaf-rhizome-root space, thus no part of the plant anatomy could be avoided in the new regenerated plantlet. First evidence came from carbon fixation experiments, since the carbon fixed at the leaf is rapidly distributed over the leaf itself, the rhizome and the roots $(50 \%$ on a FW basis). Second, the experiments of addition of $\mathrm{N}$ and $\mathrm{P}$ support that these appeared to fulfil most of the requirements of the cultivated explants (94\% of the variable $\mathrm{GH}$ explained). In spite of $\mathrm{N}$ and $\mathrm{P}$ content of our C. nodosa (Fig. 3. and data from reference laboratory $\% \mathrm{~N}=1.49 \pm 0.009 ; \% \mathrm{P}=0.146 \pm$ 0.0001 ; mean \pm S.E.) may support for its consideration as nutrient depleted plants (Duarte, 1990) the cultivated explants seem not assimilated well nutrient enrichment. On the contrary, as seen in Fig. 3, without any increase in biomass that might dilute assimilated nutrients, a rapid (48 h) decrease in P nutrient status might be promoted in the cultivated plant, unless $\mathrm{P}$ addition was provided to the underground tissue or kinetin was present in the water.

The respective role and interaction of the aboveground and underground tissue on the physiological performance of seagrasses has been a matter for significant ecological concern (Pérez et al., 1994; Terrados and Williams, 1997; Terrados et al., 1997; Kraemer and Mazzella, 1999; Touchette and 
Burkholder, 2000a,b). In vitro, it has not been so extensively studied but it should be noted that Bird et al. (1998) reported that $H$. decipiens in stage II of propagation progressed further to the acclimatisation stage, since it spontaneously rooted. Perhaps, it progressed spontaneously precisely because it rooted.

In conclusion, $C$. nodosa in vitro cultures were established at stage I from apical and ramet explants which were reactive to growth substances, but further propagation to stages II and II was not achieved. Instead, the experiments with ramet explants to mimic stage II plantlet revealed that there seems to be a close interconnection within the leaf-rhizome-root that affects photosynthetic performance and mineral nutrition, thus suggesting that no one part of the plant anatomy could be avoided in the new regenerated plantlet in vitro.

\section{Acknowledgement}

This work was financed by the INNOVA research programme of the Fundación Universitaria de Las Palmas de Gran Canaria.

\section{Appendix A. Supplementary data}

Supplementary data associated with this article can be found, in the online version, at doi:10.1016/j.aquabot.2005.07.006.

\section{References}

Agrawal, A., Mohan Ram, H.Y., 1995. In vitro germination and micropropagation of water chestnut (Trapa sp.) Aquat. Bot. 51, 135-146.

Balestri, E., Bertini, S., 2003. Growth and development of Posidonia oceanica seedlings treated with plant growth regulators: possible implications for meadow restoration. Aquat. Bot. 76, 291-297.

Bird, K.T., Cody, B.R., Jewett-Smith, J., Kane, M.E., 1993. Salinity effects on Ruppia maritima L. cultured in vitro. Bot. Mar. 36, 23-28.

Bird, K.T., Brown, M.S., Henderson, T.T., O'Hara, C.E., Robbie, J.M., 1996. Culture studies of Ruppia maritima L. in bicarbonate and sucrose-based media. J. Exp. Mar. Biol. Ecol. 199, 153-164.

Bird, K.T., Johnson, J.R., Jewett-Smith, J., 1998. In vitro culture of the seagrass Halophila decipiens. Aquat. Bot. 60, 377-387.

Box, G.E.P., Behnken, D.W., 1969. Some new three level designs for the study of quantitative variables. Technometrics 2, 455-457.

Chevreau, E., Skirvin, R.M., Abu-Qaoud, H.A., Korban, S.S., Sullivan, J.G., 1989. Adventitious shoot regeneration from leaf tissue of three pear (Pyrus sp.) cultivars in vitro. Plant Cell Rep. 7, 688-691.

Duarte, C.M., 1990. Seagrass nutrient content. Mar. Ecol. Prog. Ser. 67, 201-207.
Huang, L.-C., Chang, Y.H., Chang, Y.L., 1994. Rapid in vitro multiplication of the aquatic angiosperm, Anubias barteri var. undulata. Aquat. Bot. 47, $77-83$.

Jeffrey, S.W., Humphrey, G.W., 1975. New spectrophotometric equations for determining chlorophylls $a, b, c$ and $c_{2}$ in higher plants, algae and natural phytoplankton. Biochem. Physiol. Pflanz. 46, 191-194.

Kane, M.E., Davis, G.L., McConnell, D.B., Gargiulo, J.A., 1999. In vitro propagation of Cryptocoryne wendtii. Aquat. Bot. 63, 197-202.

Kraemer, G.P., Mazzella, L., 1999. Nitrogen acquisition, storage, and use by the co-occurring Mediterranean seagrasses Cymodocea nodosa and Zostera noltii. Mar. Ecol. Prog. Ser. 183, 95-103.

Koch, E.W., Durako, M.J., 1991. In vitro studies of the submerged angiosperm Ruppia maritima: auxin and cytokinin effects on plant growth and development. Mar. Biol. 110, 1-6.

Loquès, F., Caye, G., Meinesz, A., 1990. Axenic culture of selected tissue of Posidonia oceanica. Aquat. Bot. 37, 171-188.

Molenaar, H., Meinesz, A., 1992. Vegetative reproduction in Posidonia oceanica. II. Effects of depth changes on transplanted orthotropic shoots. Mar. Ecol. 13, 175-185.

Molenaar, H., Meinesz, A., 1995. Vegetative reproduction in Posidonia oceanica survival and development of transplanted cuttings according to different spacings, arrangements and substrates. Bot. Mar. 38, 313-322.

Molenaar, H., Meinesz, A., Caye, G., 1993. Vegetative reproduction in Posidonia oceanica. Survival and development in different morphological types of transplanted cuttings. Bot. Mar. 36, 481-488.

Pérez, M., Duarte, C.M., Romero, J., Sand-Jensen, K., Acoverro, T., 1994. Growth plasticity in Cymodocea nodosa stands: the importance of nutrient supply. Aquat. Bot. 47, 249-264.

Provasoli, L., 1968. Media and prospects for the cultivation of marine algae. In: Watanabe, A., Hattori, A. (Eds.), Cultures and Collection of Algae. Japanese Society of Plant Physiologists, Tokyo, pp. 63-67.

Robaina, R.R., García, P., García-Reina, G., Luque, A., 1990. Morphogenic effect of glycerol on tissue culture of the red seaweed Grateloupia doryphora. J. Appl. Phycol. 2, 137-143.

Terrados-Muñoz, J., 1995. Effects of some plant growth regulators on the growth of the seagrass Cymodocea nodosa (Ucria) Ascherson. Aquat. Bot. 51, 311-318.

Terrados, J., Williams, S.L., 1997. Leaf versus root nitrogen uptake by the surfgrass Phyllospadix torreyi. Mar. Ecol. Prog. Ser. 149, 267-277.

Terrados, J., Duarte, C.M., Kenworthy, W.J., 1997. Is the apical growth of Cymodocea nodosa dependent on clonal integration? Mar. Ecol. Prog. Ser. 158, 103-110.

Touchette, B.W., Burkholder, J.M., 2000a. Review of nitrogen and phosphorus metabolism in seagrasses. J. Exp. Mar. Biol. Ecol. 250, 133-167.

Touchette, B.W., Burkholder, J.M., 2000b. Overview of the physiological ecology of carbon metabolism in seagrasses. J. Exp. Mar. Biol. Ecol. 250, 169-205.

Walinga, I., Van Der Lee, J.J., Houba, V.J.G., Van Vark, W., Novozamsky, I., 1995. Plant Analysis Manual. Kluwer Academic Publisher, London, pp. 17-33.

West, R.J., Jacobs, N.E., Roberts, D.E., 1990. Experimental transplanting of seagrasses in Botany Bay, Australia. Mar. Poll. Bull. 21, 197-203. 